\title{
The Boys Club: Engineering a More Positive Environment for Women in Male-Dominated Majors
}

\author{
Brooke E. Dresden ${ }^{1, *}$, Alexander Y. Dresden ${ }^{2}$ and Robert D. Ridge ${ }^{1}$ \\ 1 Department of Psychology, Brigham Young University, Provo, UT 84602, USA; bob_ridge@byu.edu \\ 2 Burrell College of Osteopathic Medicine, 3501 Arrowhead Dr, Las Cruces, NM 88001, USA; \\ alexander.dresden@mybcom.org \\ * Correspondence: brooke.dresden@byu.net; Tel.: +1-385-312-4464
}

Received: 15 December 2017; Accepted: 24 January 2018; Published: 26 January 2018

\begin{abstract}
Sexual harassment has been widely studied in the workforce, but the factors that contribute to hostile educational environments for women have received less attention. The present study focuses on male dominance, gender harassment, gender threats, masculinity, and their influences on creating a hostile environment for women in academia. One hundred and forty-two male participants from a private university in the Southwestern United States self-reported their masculinity, completed a group task with a female confederate leader serving as a gender threat in half the conditions, and had their subsequent affect, perceptions of leadership effectiveness, and behavioral aggression measured. Men from male-dominated majors and men who had received a gender threat did not differ from men from gender-equivalent majors and men who had not received a gender threat on affect, perceptions of leadership effectiveness, or behavioral aggression ( $\mathrm{ps}>0.201, \eta \mathrm{p} 2 \mathrm{~s} \leq 0.007$ ). However, post-hoc analyses revealed that as masculinity increased among men from male-dominated majors under gender threat, they became significantly more behaviorally aggressive $(b=5.92, p=0.003)$ and perceived their female leader as less effective $(b=-0.83, p=0.076)$. Implications and suggestions for future research are discussed.
\end{abstract}

Keywords: behavioral aggression; course selection; gender; gender threat; hostile environment; male dominance; masculinity; sexual harassment; STEM

\section{Introduction and Literature Review}

The sexual harassment awareness campaign \#MeToo was named Time's Person of the Year for 2017, and its impact continues to spread around the globe (Zacharek et al. 2017). With more people than ever discussing harassment and its potential impacts, it is a pivotal time for research on the issue. One factor that has been demonstrated to lead to harassment in the workplace is female underrepresentation or male dominance (De Haas and Timmerman 2010; Fouad and Singh 2012; Gruber and Morgan 2005; Kabat-Farr and Cortina 2014; Stockdale et al. 1999). In the workforce, women in male-dominated environments are more likely to experience a hostile work environment, a form of sexual harassment recognized by the Equal Employment Opportunity Commission (EEOC), and report experiences that include, but are not limited to, doubts about their legitimacy and competence, blocked access to promotion, and personal hostility as they demonstrate proficiency in male-typed tasks (Heilman et al. 2004; McLaughlin et al. 2012; Taylor 2016; Rudman and Glick 1999). Additionally, women are rated as less effective in leadership positions when their organizations are male-dominated (Bartol 1999).

Whereas harassment that occurs in the workforce has been heavily focused upon by previous research and the media, recent research regarding the experiences of women in academia demonstrated that reports of gender harassment in male-dominated majors are significantly higher than those in gender-equivalent majors at our universities (Dresden et al. 2017). In 2013, men accounted for only 
$42.7 \%$ of bachelor's degrees in all fields, but $82.1 \%$ in computer science, $80.7 \%$ in engineering, $61 \%$ in physical sciences, and $57 \%$ in mathematics (National Science Board NSB). This male domination may have unwittingly fostered an atmosphere that is not female-friendly and created issues related to the retention of female students. In science, technology, and engineering (STEM) majors, which are traditionally male-dominated, proportionally more females than males switch to non-STEM majors, and within engineering, approximately $14 \%$ of women who graduate never enter the workforce in that field (Chen and Soldner 2013; Fouad and Singh 2012). Among the 14 percent who leave engineering, a significant proportion report the "engineering culture" as their main reason for leaving (Fouad and Singh 2012).

In these male-dominated environments, women may be viewed as a gender threat, or a threat to masculinity, by their male counterparts, resulting in increased hostility toward them and the creation of a negative work environment. These women are especially at risk when they occupy positions of leadership (Bartol 1999; Eagly and Karau 2002). Gilmore (1990) argues that "real manhood ... is a precarious or artificial state that boys must win against powerful odds" (p. 11). Thus, masculinity is a social construction, and it must be earned and protected (Vandello et al. 2008). When it is threatened, men will go to great lengths to defend against the threat. For example, Bosson et al. (2009) found that men who experienced a gender threat, in the form of a hair braiding activity, subsequently chose to complete a physically aggressive boxing activity at a significantly higher frequency than men who did not receive a gender threat. Similar results were obtained by Funk and Werhun (2011), who found that men squeezed a handgrip much more forcefully if they had been told that they "squeezed like a girl" on their first attempt.

Not only do men react behaviorally to restore their masculinity in the presence of a gender threat, but they also react cognitively and affectively. Vandello et al. (2008) gave men feedback that their performance was atypical on a gender knowledge test and then had them engage in a word completion task. Men who received the atypical feedback nearly doubled the number of aggressive words they completed relative to women who received atypical feedback, suggesting that men, but not women, experience heightened aggressive cognition when their gender status was threatened. In addition, men who were told that they had received a score similar to that of a woman on the gender knowledge test completed significantly more word fragments with anxiety-related words, suggesting a negative emotional reaction to the threat. This literature suggests that gender threats, or threats to masculinity, are powerful predictors of increased anxiety and stress, as well as aggressive cognition and behavior, in men (Bosson et al. 2009; Funk and Werhun 2011; Michniewicz et al. 2014).

The purpose of this study is to introduce a realistic gender threat in the laboratory and analyze whether men in male-dominated majors will be primed to perceive the threat as more severe than men in gender-equivalent majors and subsequently behave more aggressively toward a female leader, have increased negative affect, and perceive their female leader as less effective. This was achieved in a blind study by creating a group task where a female confederate was chosen as the leader, ostensibly based upon her higher scores on masculine leadership traits, and three male participants, from either male-dominated or gender-equivalent majors, performed a task under her supervision. Following the task, and the revelation that the group performed poorly, the male participants were asked to rate their female leader's leadership effectiveness as well as their current affect. Finally, each participant engaged in a task which measured behavioral aggression toward the female leader. Academia is a crucial place to focus this research because it is a weeder for those who will actually end up in the workforce; thus, providing a window of opportunity to support and educate male and female students and hopefully prevent issues related to sexual harassment in the future.

Combining the literature on male dominance and gender threats, we hypothesize that men in a gender threat condition will be more aggressive toward their female leader, report more negative affect, and perceive their female leader as less effective than men in a low gender threat condition (Hypothesis 1). Additionally, we hypothesize that men from male-dominated majors will be more aggressive toward their female leader, report more negative affect, and perceive their female leader 
as less effective, than men from gender-equivalent majors (Hypothesis 2). We also anticipate that these main effects will be moderated by a significant interaction wherein men in the high gender threat condition who are from male-dominated majors will be the most aggressive (Hypothesis 3), report the most negative affect (Hypothesis 4), and perceive their female leader as the least effective (Hypothesis 5).

\section{Method}

\subsection{Participants}

One hundred and forty-two male participants from a large private university in the Southwestern United States participated in the study (see Table 1 for participant details). All participants were current undergraduate students from male-dominated and gender-equivalent majors. Consistent with the definition created by the Department of Labor (2009), male-dominated majors were operationally defined as consisting of $75 \%$ or more males, whereas gender-equivalent majors consisted of a maximum of $60 \%$ of a single gender. Participants were randomly assigned to a high gender threat or low gender threat condition, resulting in four possible conditions: high gender threat/male-dominated major (35 participants), high gender threat/gender-equivalent major (37 participants), low gender threat/male-dominated major (35 participants), and low gender threat/gender-equivalent major (35 participants).

Table 1. Demographic characteristics of participants.

\begin{tabular}{ll}
\hline \multicolumn{1}{c}{ Characteristic } & \multicolumn{1}{c}{$N$ (\%) } \\
\hline \multicolumn{1}{c}{$(N=142)$} \\
\hline Major Classification & \\
\hline Male Dominant & $70(49.30 \%)$ \\
Gender Equivalent & $72(50.70 \%)$ \\
\hline Race/Ethnicity & \\
\hline Caucasian & $126(88.73 \%)$ \\
Hispanic/Latino & $5(3.52 \%)$ \\
Asian & $4(2.83 \%)$ \\
African American & $2(1.41 \%)$ \\
American Indian/Alaskan Native & $2(1.41 \%)$ \\
Other & $1(0.70 \%)$ \\
\hline Year in School & \\
\hline Senior & $46(32.39 \%)$ \\
Junior & $47(33.10 \%)$ \\
Sophomore & $30(21.13 \%)$ \\
Freshman & $18(12.68 \%)$ \\
Other & $1(0.70 \%)$ \\
\hline Marital Status & \\
\hline Never married & $99(69.73 \%)$ \\
Married & $39(27.47 \%)$ \\
Other & $1(0.70 \%)$ \\
Mean Age & 22.69 years \\
\hline
\end{tabular}

\subsection{Procedure}

Participants were recruited using flyers and email announcements within individual undergraduate departments after the study received approval from the Institutional Review Board (approval number: $F$ 15284). Upon arrival to the computer laboratory, participants were asked to read and sign an informed consent form prior to study participation. Participants were then placed in a group with two other men from their major classification (male-dominated or gender-equivalent) as well as a female confederate. 
Participants sat at their individual computers as they were informed that the ostensible purpose of the study was to better understand how well students can perform in a group while working on an online system rather than meeting in person. They were also told that following the group task and an evaluation of their group performance level, their individual performance level would be measured on a separate task.

\subsubsection{Masculinity and Femininity}

Participants first completed the masculinity and femininity measure, disguised as a simple personality questionnaire, which would be used later in the study to induce a gender threat. Developed by Williams and Best (1990), this measure includes 18 characteristics that have been identified cross-culturally as masculine and feminine (nine masculine characteristics and nine feminine characteristics). An updated version replacing dated terms like "poised" and "disorderly" with "graceful" and "rowdy" was created by Bosson and Michniewicz (2013) and was used in the present study. The Cronbach's alpha was 0.74 for the masculinity scale and 0.80 for the femininity scale. After the questionnaires were completed, the participants and confederate gathered around a table at the front of the room and a group leader was assigned.

\subsubsection{Threat Manipulation}

In the high gender threat condition, participants were informed that the female confederate was chosen as the group leader based on her higher scores on leadership traits as assessed by the personality questionnaire completed at the beginning of the study. Specifically, it was stated that she scored higher on the traits of assertiveness, capability, independence, and rationality. Past research has found that these leadership traits are generally recognized as masculine (Bosson and Michniewicz 2013). To further exacerbate the gender threat, the female confederate was moved to a slightly taller chair at the head of the table.

In the low gender threat condition, participants were informed that they all had an equal chance of becoming the leader, but the female confederate had been randomly assigned as their leader. In this condition, the female leader sat in a chair at equal level with the other participants. Due to the fact that the male participants in the low gender threat condition were not receiving feedback that the female confederate had scored higher than they on traditionally masculine leadership traits (the operationally defined gender threat), far less, and perhaps no, gender threat should exist.

After assigning the female leader, the researcher read a brief overview of the task to the group of participants, which read:

For the group task, we will provide the group a passage to read and answer questions from. Your leader will choose either a historical passage or a romantic tragedy. Your leader will then assign different segments of the reading to each person to read via Gmail chat. You will read your separate segments, and then come together as a group online, using Gmail chat, to discuss your individual section and answer 10 questions.

Participants were informed in all conditions that the leader would serve in a more supervisory role by choosing the content for the group task, emailing individual reading sections to each group member, keeping track of time, recording group responses for the ten-question quiz, and compiling and reviewing the group's responses before submitting them to the researcher. Although the female leader would have access to the entire reading, it was made clear that she was not to actively participate in group discussion.

The participants were further instructed that each of them would be receiving a unique section of the reading, and although they could refer back to their own section in order to answer test questions, they could not share their reading with any of their group members nor copy and paste any section of their reading into the discussion. The answers to the test questions were each located in different 
sections throughout the reading. This strategy effectively removed any certainty from the individual participants that their group had answered every question correctly.

The female leader was then provided the options of either a historical piece of writing on the American Revolution or a romantic tragedy for the group task. In all conditions, the female confederate chose the historical writing. She was then asked to parcel out reading assignments to her team. The group members returned to their individual computers, and each male participant was assigned to read the piece of text provided to him by the female confederate leader via email.

After participants had completed their assigned reading (three minutes), they were asked to use Gmail chat, which was already set up for them, and respond to 10 test questions regarding the reading. As previously mentioned, each participant had a unique section of the reading, and the group had to work together to decide what the correct answer was for each item, forcing them to rely on each other's knowledge and also creating an environment where no one individual would have direct access to every correct answer. Participants simulated an online group project by wearing noise-canceling headphones and only communicating via instant messaging. As the group members discussed the answers, the female leader maintained a supervisory role by viewing the ongoing discussion, recording the participants' answers to each question, and updating the group on the remaining time. After approximately seven minutes, the researcher gave the official word to the group that time was up and asked the female group leader to look over the group's responses and decide if any changes needed to be made before submitting them. The group leader had approximately two minutes to do so. While the group leader was ostensibly looking over their test answers, the other group members were asked to sit quietly for two minutes.

After the group leader submitted the test answers, the researcher took a few moments to ostensibly grade the group's test. In reality, none of the tests were graded, and every group was informed that they had received the same score. After the "grading" was complete, the researcher informed the group that they had "scored below average with a score of 7/10 (70\%) correct, or a C-".

\subsubsection{Positive and Negative Affect Schedule (PANAS)}

After receiving this negative feedback, participants were asked to answer a few survey questions regarding their feelings following the group task, their overall group experience, and the effectiveness of their group members and group leader. In order to assess their negative affect, participants completed an online version of the PANAS, a 20-item self-report measure of mood, which produces two distinct scores for positive and negative affect (Watson et al. 1988). The Cronbach's alphas were 0.90 and 0.83 , respectively.

\subsubsection{Perceived Leadership Effectiveness Scale (PLES)}

Participants were asked to rate their group experience on a variety of dimensions (e.g., enjoyable, effective, willingness to work together again) as well as the effectiveness of their team leader using the PLES. Questions were added within the Perceived Leadership Effectiveness Scale regarding group effectiveness in order to disguise the true purpose of the scale. The PLES is a six-item self-report measure regarding perceived leadership effectiveness (Giessner and van Knippenberg 2008). The Cronbach's alpha for the PLES was 0.89 .

\subsubsection{Competitive Reaction Time Task (CRTT)}

Participants were then informed that their performance would now be measured at an individual level by completing a competitive task. For this task, participants remained at their computers, and each participant was handed a slip of paper that informed them that they had been randomly assigned to compete against one member of their team. In reality, all participants were assigned to compete against their female group leader in the CRTT. The CRTT, originally created by Epstein and Taylor (1967), allows participants to supposedly "compete" against another participant in a reaction time task. In the CRTT, a colored box changes from green, to yellow, to red, and the participant is told to click on 
the screen as soon as the box turns red. The participant is told that the individual with the quickest reaction time will win the task. The participant plays the CRTT 25 times and is randomly assigned to lose the task 12 of those times. Upon losing, the participant is blasted by an unpleasant white noise ostensibly selected by their partner. Upon winning, the participant is able to choose the intensity (0-10 intensity) and duration ( $0-5 \mathrm{~s})$ with which their opponent will be noise blasted. Following the scoring method for the CRTT used by Bushman and Baumeister (1998), participants received a score based on the sum of the intensity and duration they chose on the first trial, providing a measure of "unprovoked" aggression.

\subsubsection{Debriefing}

After the CRTT was completed, participants were debriefed online as to the actual purpose of the study and provided the opportunity to have their data removed from analysis. Before leaving the study area, all participants were either monetarily compensated with $\$ 10$ or received course credit if enrolled in a course that required participation in a study.

\section{Results}

The primary purpose of this experiment was to determine the influence of gender threat and male dominance within a major on subsequent behavior, affect, and cognition. For the purposes of analysis, participants were separated by enrollment in a male-dominated or gender-equivalent major and receipt of a high or low gender threat, resulting in 2 (major classification: male-dominated, gender-equivalent) $\times 2$ (condition: high gender threat, low gender threat) factorial design. Using Stata Statistical Software, three separate analyses of variance (ANOVAs), instead of a single MANOVA, were run for each dependent variable due to the existence of separate a priori hypotheses.

\subsection{Hypotheses}

In order to test Hypotheses 1 and 2, that men in the high gender threat condition and men from male-dominated majors will be more aggressive toward their female leader, have more negative affect, and perceive their female leader as less effective, than men in the low gender threat condition and men from gender-equivalent majors (i.e., significant main effects), and Hypotheses 3, 4, and 5, that an interaction will exist wherein men in the gender threat condition who are from male-dominated majors will be the most aggressive, the DV's were submitted as the dependent variables to separate 2 (major classification: male-dominated, gender-equivalent) $\times 2$ (condition: high gender threat, low gender threat) ANOVAs. The results revealed no significant main effects or interactions, all $\mathrm{F}^{\prime} \mathrm{s}(1,138)<0.35$, ps $>0.554$, thus failing to support our a priori hypotheses.

\subsection{Post-Hoc Analyses}

Although our hypotheses did not return significant results, recent research on the influence of traditional masculinity suggests that conformity to traditional masculine norms may moderate relationships between behavioral aggression and many other factors, including playing violent video games and being exposed to gender threats (Hunt and Gonsalkorale 2014; Thomas and Levant 2012). Following this line of research, we investigated the effects of self-reported masculinity related to behavioral aggression as post-hoc analyses. Preliminary $t$-test analyses on the self-report masculinity and femininity variables indicated no significant difference between male-dominated and gender-equivalent majors on self-reported masculinity $\mathrm{t}(140)=-0.10, p=0.918, \mathrm{~d}=-0.02,95 \% \mathrm{CI}$ $[-0.18,0.16]$, with males from male-dominated majors $(\mathrm{M}=3.84, \mathrm{SD}=0.53)$ self-reporting masculinity essentially equal to that of men from gender-equivalent majors $(M=3.85, S D=0.50)$. However, a significant difference emerged between male-dominated majors and gender-equivalent majors in regards to self-reported femininity $\mathrm{t}(140)=-3.70, p<0.001, \mathrm{~d}=-0.63,95 \% \mathrm{CI}[-0.51,-0.15]$, with males from male-dominated majors $(\mathrm{M}=3.45, \mathrm{SD}=0.59)$ self-reporting significantly less 
femininity than men from gender-equivalent majors $(M=3.78, S D=0.47)$, indicating that men from gender-equivalent majors were relatively more androgynous than men from male-dominated majors.

With the knowledge that men from the two major classifications did not differ significantly on self-reported masculinity, we correlated masculinity with behavioral aggression, negative affect, and the perception of the female leader's leadership effectiveness within each of the four experimental conditions (male-dominated, high gender threat; gender-equivalent, high gender threat; male-dominated, low gender threat; gender-equivalent, low gender threat). The correlation matrix revealed a large (Cohen 1988), significant correlation between self-reported masculinity and behavioral aggression $(\mathrm{r}=0.49, p=0.003)$, as well as a similar trend between self-reported masculinity and perceptions of leadership effectiveness $(r=-0.30, p=0.076)$, among men from male-dominated majors who had received a gender threat (see Table 2), but no significant correlations in any of the other three groups, suggesting that as a gender threat is introduced to men from male-dominated majors, an increase in self-reported masculinity corresponds to an increase in behavioral aggression toward the female confederate and a decrease in their perception of her leadership effectiveness. Negative affect did not correlate with the other variables.

Table 2. Correlation table.

\begin{tabular}{|c|c|c|c|c|c|}
\hline Group & Measures & 1 & 2 & 3 & 4 \\
\hline $\begin{array}{l}\text { Male-dominated Major, Gender Threat } \\
\qquad \mathrm{n}=35\end{array}$ & $\begin{array}{l}\text { 1. Masculinity } \\
\text { 2. Behavioral Aggression } \\
\text { 3. Negative Affect } \\
\text { 4. Perception of Leadership Effectiveness }\end{array}$ & $\begin{array}{l}0.49^{* *} \\
-0.09 \\
-0.30\end{array}$ & $\begin{array}{c}-0.01 \\
-0.38^{*}\end{array}$ & -0.34 * & \\
\hline
\end{tabular}

Following the findings within the correlation matrix, a multivariate multiple regression was conducted to predict the three dependent variables (behavioral aggression, negative affect, and perceptions of leadership effectiveness) from self-reported masculinity within each group. A significant regression equation was found among men in male-dominated majors who had received a gender threat $(b=5.92, t(31)=3.26, p=0.003)$, but not among any of the other three groups (see Table 3$)$.

Table 3. Multiple multivariate regression analysis of factors related to self-reported masculinity.

\begin{tabular}{|c|c|c|c|c|c|c|}
\hline \multirow{2}{*}{$\begin{array}{c}\text { Group } \\
\begin{array}{c}\text { Male-dominated Major, Gender Threat } \\
\mathrm{n}=35\end{array}\end{array}$} & & $b$ & $\mathrm{SE} b$ & $\mathbf{t}$ & \multicolumn{2}{|c|}{$95 \%$ CI } \\
\hline & $\begin{array}{c}\text { Behavioral Aggression } \\
\text { Negative Affect } \\
\text { Perception of Leadership Effectiveness }\end{array}$ & $\begin{array}{c}5.92^{* *} \\
-0.97 \\
-0.83^{+}\end{array}$ & $\begin{array}{l}1.81 \\
1.80 \\
0.45\end{array}$ & $\begin{array}{l}3.26 \\
-0.54 \\
-1.83\end{array}$ & $\begin{array}{l}2.23 \\
-4.64 \\
-1.75\end{array}$ & $\begin{array}{l}9.61 \\
2.70 \\
0.09\end{array}$ \\
\hline
\end{tabular}

Masculinity significantly predicted whether participants from male-dominated majors who had received a gender threat were more behaviorally aggressive and explained a significant proportion of the variance $\left(\mathrm{R}^{2}=0.244, \mathrm{~F}(1,31)=10.63, p=0.003\right)$.

Additionally, the multivariate multiple regression produced a marginally significant relationship among men in male-dominated majors who had received a gender threat $(B=-0.83, t(31)=-1.83$, $p=0.076)$, but not among any of the other three groups. Masculinity marginally predicted whether participants from male-dominated majors who had received a gender threat perceived their leader as less effective and explained a marginally significant proportion of the variance $\left(R^{2}=0.093\right.$, $\mathrm{F}(1,31)=3.37, p=0.076$; see Table 3$)$. 


\section{Discussion}

Contrary to our hypotheses, men who experienced a high gender threat and men from male-dominated majors did not exhibit more behavioral aggression, increased negative affect, or decreased perceptions of leadership effectiveness toward a female confederate than men who did not receive a gender threat and men from gender-equivalent majors, and there was no interaction between the variables. It appears that the combination of gender threat with enrollment in a male-dominated major did not affect men's negative behavior toward a female leader. However, post-hoc analyses incorporating self-reported masculinity as a moderator revealed that as self-reported masculinity increased among men who had experienced a high gender threat and came from a male-dominated major, as did their behavioral aggression, while their perceptions of a female leaders' effectiveness decreased. This relationship was not present among men in any other combination of threat and major, suggesting that the high gender threat and type of major may affect behavior and cognition but only for a specific group of self-reported "masculine" men. We offer this interpretation tentatively, as these results were the results of post-hoc analyses and were not part of our original hypotheses. Consequently, we are cautious about the implications of these findings.

For men from male-dominated majors who experienced a high gender threat, higher self-reported masculinity predicted increased behavioral aggression toward their female leader as well as decreased perceptions of leadership effectiveness. These findings are consistent with the original hypotheses and background research for this study, which suggested that the interaction between male dominance and a gender threat would lead to an increase in behavioral aggression; however, the influence of masculinity was not initially addressed. It is interesting and important to note that whereas high masculinity has often been associated with increased aggression (Sears 2013; Weisbuch et al. 1999), self-reported masculinity in this study was equal for the gender-equivalent and male-dominated majors, but only affected behavioral aggression for the male-dominated majors under gender threat.

These findings make a case for the negative influence of numerical and normative male dominance when a gender threat is presented to men who self-report as high on masculinity. As shown by their behavioral aggression scores, the gender threat impacted men from male-dominated majors on a scale relative to their self-reported masculinity. As discussed in the literature review, Schultz (1998) asserted that "a drive to maintain the most highly rewarded forms of work as domains of masculine competence underlies many, if not most, forms of sex-based harassment on the job" (p. 1755). Although physical aggression cannot be equated to a hostile work environment, the physical aggression demonstrated in this study suggests a desire to "punish" the female leader. Based on Schultz's assertion, men higher in masculinity, who view their major as a masculine domain, may feel a greater drive to maintain that domain of masculine competence, creating a potentially hostile environment for female counterparts. When men are already in a numerically and normatively male-dominated environment, the introduction of a female leader may be perceived as a gender threat for men high on masculinity and may result in increased behavioral aggression and a perception of the female leader as less effective, potentially resulting in a hostile work environment for their female counterparts.

Another significant contribution is the identification of appointed female leaders as a gender threat among men from male-dominated majors who self-rate as high on masculinity. A gender threat has not, to our knowledge, been presented in previous research in such a subtle but potentially powerful manner. In this study, men had a real choice as to whether they would perceive the appointment of a female leader with traditionally masculine leadership qualities as a gender threat, much like they would encounter in academia or the workforce. It is generally understood in the sexual harassment literature that although sexual harassment, specifically gender harassment, is more prevalent in male-dominated workforces, not all men in those fields are guilty of harassment. The fact that a select group of men, namely men from male-dominated majors who self-identified as highly masculine, apparently perceived their female leader as a gender threat and reacted aggressively toward her behaviorally and in their leadership ratings, sheds additional light on the types of toxic situations in academia and the workforce that may result in a hostile working environment. 
This toxic situation is a difficult one to overcome. Male-dominated environments could be made to be more gender-equivalent by introducing more females, but as this study demonstrates, these women may be perceived as gender threats and experience a hostile working environment. One solution may be creating the appropriate type of contact between men and women that does not result in a gender threat. Allport (1954) introduced contact theory and four factors that can contribute to positive contact: equal status, intergroup cooperation, supportive norms, and acquaintanceship. In the case of gender harassment in academia and the workforce, focusing on supportive norms and acquaintanceship would likely be of the most use. Professors and teaching assistants in academia, as well as bosses and supervisors in the workforce, can demonstrate supportive norms by modeling appropriate intergroup behavior and encouraging positive intergroup behavior from their students and employees (Salomon and Cairns 2010). In academia, this may be demonstrated by professors who actively work with and acknowledge female students and encourage their male students to do the same. Female professors may have an especially profound impact by creating role models for female students and providing a positive female leader archetype for male students. Acquaintanceship is probably the most important of the four factors in this scenario because it can potentially help overcome the gender threat created by female leaders in male-dominated environments. The acquaintanceship factor in contact theory suggests that superficial contact between men and women in male-dominated environments may actually increase stereotypes. This may be the case when a female leader, like in the present study, maintains a strictly supervisory role and has no substantive interactions with her male counterparts. In contrast to superficial contact, creating acquaintanceship by sharing interpersonal information and creating friendships may reduce prejudice and is the most important of the four factors in contact theory because it has the potential for lasting attitude change (Salomon and Cairns 2010).

Although this strategy may be effective, it highlights the trap that women can be placed in within male-dominated fields where masculine leadership qualities are valued but the display of those qualities may result in a gender threat among their male counterparts, resulting in lower perceived leadership effectiveness and an increased risk of gender harassment. This situation is an unfair burden placed on female leaders, as opposed to male leaders, and continued research is needed to even the playing field.

\section{Future Research}

Future research should focus specifically on men who are from male-dominated majors and high on masculinity as they are the group most at risk of perceiving gender threats, which may result in negative outcomes. Future research could also focus on more diverse samples of male students, as well as incorporating diversity as a factor among the female confederates. Additionally, future research could include a longitudinal or cross-sectional study design in order to better understand the development of implicit and explicit biases in this group of men and follow their progression through male-dominated college majors and into the workforce. Such a study would have the potential to identify when explicit and implicit biases begin to emerge and whether they increase with tenure in a male-dominated field. Additionally, these studies could focus on working to diminish felt threat among this specific group of men through bias workshops, which have had success reducing harassment long-term in recent research (Carnes et al. 2015; Fine et al. 2014).

Acknowledgments: This research was partially supported by funding from the Brigham Young University Department of Psychology, as well as the Brigham Young University Women's Studies and Graduate Studies programs.

Author Contributions: All authors designed the research, reviewed, and approved the manuscript. Brooke Dresden conducted data collection, cleaning, analyses, and drafting of the manuscript. Alexander Dresden also conducted data cleaning and analyses.

Conflicts of Interest: The authors declare no conflict of interest. 


\section{References}

Allport, Gordon W. 1954. The Nature of Prejudice. Cambridge: Addison-Wesley Pub.

Bartol, Kathryn M. 1999. Gender influences on performance evaluations. In Handbook of Gender E Work. Edited by Gary N. Powell. Thousand Oaks: SAGE Publishing, pp. 165-78.

Bosson, Jennifer K., and Kenneth S. Michniewicz. 2013. Gender dichotomization at the level of ingroup identity: What it is, and why men use it more than women. Journal of Personality and Social Psychology 105: 425-42. [CrossRef] [PubMed]

Bosson, Jennifer K., Joseph A. Vandello, Rochelle M. Burnaford, Jonathan R. Weaver, and S. Arzu Wasti. 2009. Precarious manhood and displays of physical aggression. Personality and Social Psychology Bulletin 35: 623-34. [CrossRef] [PubMed]

Bushman, Brad J., and Roy F. Baumeister. 1998. Threatened egotism, narcissism, self-esteem, and directed and displaced aggression: Does self-love or self-hate lead to violence? Journal of Personality and Social Psychology 75: 219-29. [CrossRef] [PubMed]

Carnes, Molly, Patricia G. Devine, Linda Baier Manwell, Angela Byars-Winston, Eve Fine, Cecilia E. Ford, Patrick Forscher, Carol Isaac, Anna Kaatz, Wairimu Magua, and et al. 2015. The effect of an intervention to break the gender bias habit for faculty at one institution: A cluster randomized, controlled trial. Academic Medicine 90: 221-30. [CrossRef] [PubMed]

Chen, Xianglei, and Matthew Soldner. 2013. STEM Attrition: College Students' Paths into and out of STEM Fields. Available online: http:/ / nces.ed.gov/pubs2014/2014001rev.pdf (accessed on 6 May 2016).

Cohen, Jacob. 1988. Statistical Power Analysis for the Behavioral Sciences. Hillsdale: L. Erlbaum Associates.

De Haas, Stans, and Greetje Timmerman. 2010. Sexual harassment in the context of double male dominance. European Journal of Work and Organizational Psychology 19: 717-34. [CrossRef]

Dresden, Brooke E., Alexander Y. Dresden, Robert D. Ridge, and Niwako Yamawaki. 2017. No girls allowed: Women in male-dominated majors experience increased gender harassment and bias. Psychological Reports. Available online: http://journals.sagepub.com/doi/abs/10.1177/0033294117730357 (accessed on 25 January 2018). [CrossRef] [PubMed]

Eagly, Alice H., and Steven J. Karau. 2002. Role congruity theory of prejudice toward female leaders. Psychological Review 109: 573-98. [CrossRef] [PubMed]

Epstein, Seymour, and Stuart P. Taylor. 1967. Instigation to aggression as a function of degree of defeat and perceived aggressive intent of the opponent. Journal of Personality 35: 265-89. [CrossRef] [PubMed]

Fine, Eve, Jennifer Sheridan, Molly Carnes, Jo Handelsman, Christine Pribbenow, Julia Savoy, and Amy Wendt. 2014. Minimizing the influence of gender bias on the faculty search process. In Gender Transformation in the Academy (Advances in Gender Research). Edited by Vasilikie P. Demos, Catherine White Berheide and Marcia Texler Segal. Bingley: Emerald Group Publishing Limited, vol. 19, pp. 267-89.

Fouad, Nadya A., and Romila Singh. 2012. Stemming the tide: Why women engineers leave (and why do they stay). Paper presented at Symposium Conducted at the Meeting of WEPAN, Columbus, OH, USA, June 25.

Funk, Leah C., and Cherie D. Werhun. 2011. "You're such a girl!" the psychological drain of gender-role harassment of men. Sex Roles 65: 13-22. [CrossRef]

Giessner, Steffen R., and Daan van Knippenberg. 2008. Perceived Leadership Effectiveness Scale [Measurement Scale]. Washington: American Psychological Association. [CrossRef]

Gilmore, David D. 1990. Manhood in the Making. New Haven: Yale University Press.

Gruber, James, and Phoebe Morgan. 2005. In the Company of Men: Male Dominance and Sexual Harassment. Boston: Northeastern University Press.

Heilman, Madeline E., Aaron S. Wallen, Daniella Fuchs, and Melinda M. Tamkins. 2004. Penalties for success: Reactions to women who succeed at male gender-typed tasks. Journal of Applied Psychology 89: 416-27. [CrossRef] [PubMed]

Hunt, Christopher J., and Karen Gonsalkorale. 2014. Who cares what she thinks, what does he say? Links between masculinity, in-group bonding and gender harassment. Sex Roles 70: 14-27. [CrossRef]

Kabat-Farr, Dana, and Lilia M. Cortina. 2014. Sex-based harassment in employment: New insights into gender and context. Law and Human Behavior 38: 58-72. [CrossRef] [PubMed]

McLaughlin, Heather, Christopher Uggen, and Amy Blackstone. 2012. Sexual harassment, workplace authority, and the paradox of power. American Sociological Review 77: 625-47. [CrossRef] [PubMed] 
Michniewicz, Kenneth S., Joseph A. Vandello, and Jennifer K. Bosson. 2014. Men's (mis)perceptions of the gender threatening consequences of unemployment. Sex Roles 70: 88-97. [CrossRef]

National Science Board (NSB). 2016. Science and Engineering Indicators 2016; Arlington: National Science Foundation (NSB-2016-1).

Rudman, Laurie A., and Peter Glick. 1999. Feminized management and backlash toward agentic women: The hidden costs to women of a kinder, gentler image of middle managers. Journal of Personality and Social Psychology 77: 1004-10. [CrossRef] [PubMed]

Salomon, Gavriel, and Ed Cairns. 2010. Handbook on Peace Education. New York: Psychology Press.

Schultz, Vicki. 1998. Reconceptualizing sexual harassment. Yale Law Journal 107: 1683-796. Available online: http:/ / digitalcommons.law.yale.edu/cgi/viewcontent.cgi?article=6002\&context=fss_paper (accessed on 8 May 2016). [CrossRef]

Sears, Dylan J. 2013. Men's Attitudes and Behavioral Conformity to Traditional Norms of Masculinity: Associations with Entitlement and Aggression. Ph.D. dissertation, Alliant International University, California School of Professional Psychology, San Francisco, CA, USA.

Stockdale, Margaret S., Michelle Visio, and Leena Batra. 1999. The sexual harassment of men: Evidence for a broader theory of sexual harassment and sex discrimination. Psychology, Public Policy, and Law 5: 630-64. [CrossRef]

Taylor, Catherine J. 2016. 'Relational by nature'? Men and women do not differ in physiological response to social stressors faced by token women. American Journal of Sociology 122: 49-89. [CrossRef]

Thomas, Kevin D., and Ronald F. Levant. 2012. Does the endorsement of traditional masculinity ideology moderate the relationship between exposure to violent video games and aggression? The Journal of Men's Studies 20: 47-56. [CrossRef]

Vandello, Joseph A., Jennifer K. Bosson, Dov Cohen, Rochelle M. Burnaford, and Jonathan R. Weaver. 2008. Precarious manhood. Journal of Personality and Social Psychology 95: 1325-39. [CrossRef] [PubMed]

Watson, David, Lee A. Clark, and Auke Tellegen. 1988. Development and validation of brief measures of positive and negative affect: The PANAS scales. Journal of Personality and Social Psychology 54: 1063-70. [CrossRef] [PubMed]

Weisbuch, Max, Daniel Beal, and Edgar C. O'neal. 1999. How masculine ought I be? Men's masculinity and aggression. Sex Roles 40: 583-92. [CrossRef]

Williams, John E., and Deborah L. Best. 1990. Sex and Psyche: Gender and Self Viewed Cross-Culturally. Thousand Oaks: Sage Publications, Inc.

Zacharek, Stephanie, Eliana Dockterman, and Haley S. Edwards. 2017. TIME Person of the Year 2017: The Silence Breakers. Available online: http:/ / time.com/time-person-of-the-year-2017-silence-breakers / (accessed on 10 December 2017).

(C) 2018 by the authors. Licensee MDPI, Basel, Switzerland. This article is an open access article distributed under the terms and conditions of the Creative Commons Attribution (CC BY) license (http://creativecommons.org/licenses/by/4.0/). 